\title{
BAYESIAN MODELS AND STOCHASTIC PROCESSES APPLIED TO CSP SAMPLING PLANS FOR QUALITY CONTROL IN PRODUCTION IN SERIES AND BY LOTS
}

\author{
Rodrigo Barbosa Correa \\ Dept. of Industrial Engineering \\ Universidad del Norte \\ Barranquilla, COLOMBIA
}

\author{
Carlos D. Paternina-Arboleda \\ Dept. of Industrial Engineering \\ Universidad del Norte \\ Barranquilla, COLOMBIA
}

Diana G. Ramírez Ríos

\author{
Dept. of Industrial Engineering \\ Universidad del Norte \\ Barranquilla, COLOMBIA
}

\begin{abstract}
Nowadays, businesses consider that their methods are perfect, this means, that by having available a department of analysis and statistic control of the process, everything that the inspector or the inspection tools decides are considered to be correct, with not even a minimum of error involved. Yet, if they considered the principles of uncertainty of Heisenberg, in which he believes that the uncertainty associated to the observation, does not contradict the existence of laws that govern the behavior of the particles in the universe, not even the capacity of the scientists to discover those laws, which will be seen as precise predictions, which can be substituted by the calculations of probabilities. This investigation focuses on the study of CSP sampling plans for acceptance with Bayesian and Markovian revisions, in the processes of production in series and by lots, that support the quality activities and reduction of costs by inspection.
\end{abstract}

\section{INTRODUCTION}

Having the knowledge of the limited literature that exists, authors, such as Roberts, S.W. (1965) and Brugger, R.M. (1972), propose chains of Markovian states as a way to evaluate the sampling plans of continuous production and by lots. Recently, it has been found that Balamurali, S. (1999) and Govindaraju K. (2007) have exposed the CSP plans adjusted to CSP sampling plans adjusted to the requirements of the client. Also, investigations done by Bidyuk, B. and Dechter, R. (2003) approach systematic reduction of sampling under Bayesian conditions, yet, as mentioned before, there is very little applied mathematically and modelistically to solve and implement sampling plans with Bayesian and Markovian revisions to the former systems of production.

In the present, by bibliographical references, mathematical and statistical studies, even the real industrial situations of continuous production and by lots, the conditional probabilities of prediction and validity, according to a Bayesian approach, do not exist. Indeed, in the businesses, inspectors and tools are used to detect non conformities and do not apply prediction conditions to reduce to the maximum the delivery of products that do not meet the standards of the client, and not even to validate statistically this situation. This is the reason why this investigation is important for the improvement of quality in the delivery of products and, in this way, looking for a solid basis for knowledge in the area of quality and operations research.

In the following paper the basic concepts and initial statistical model of a CSP-1 plan will be described and the Bayesian analysis of the inspection situations.

\subsection{Markov Theory and the Markovian state chains}

Due to the subject that this investigation emphasizes, it is necessary to define some fundamental concepts and understand the stochastic process that is defined as an indexed collection of random variables $\left(\mathrm{X}_{\mathrm{t}}\right)$, where each index $\mathrm{t}$ takes values from a given set $T$. With frequency $T$ is taken as a non negative set of integers and $X_{t}$ represents a characteristic of interest, measurable in time $t$, reason why, due to its random and probabilistic nature, it can take any $\mathrm{X}_{\mathrm{i}}$.

\subsection{Sampling plans for the Average Outgoing Quality (AOQ) for production in series and by lots}

In many manufacturing operations cases, the lots do not get involved in the production process, instead they are obtained through production by series, band transportation or lines of production. For continuous production, inspection plans have been designed, which were established by Harold F. Dodge in 1943 and whose modifications have been done in Dodge, H. F. 
and Torrey, M. N. (1951), and, in addition to this, the work done Lieberman, G. J. and Solomon, H. (1955). Between these plans, the so called CSP can be found.

The CSP plans designed and implemented are CSP-1, CSP- 2, CSP- 3, CSP in a multiple level, CSP- F, CSP- T and CSP- V, which contain between them, some differences due to the implementation and the theoretic foundation between them. The following describes the CSP-1 plans.

1. This plan starts with the inspection of $100 \%$ of the product in the order according to the order of the production. As soon as the "i" consecutive units with defects have been inspected, only a fraction of them, "f", are inspected. "f" represent the frequency of the sampling or the ratio of inspected units to the total quantity of units that pass through a line of production, where there an inspection during the periods of the inspection by sampling. This has to be done by selecting the sample individual units, one instead of the production flow, in order to make sure technically that the sample is centrally distributed. These values for " $\mathrm{i}$ " and " $\mathrm{f}$ " are chosen instead of the LCPS or AOQL given and the combination of them allows for a better diversity in the application of sampling plans.

2. If a simple unit is found to be defective, immediately the $100 \%$ inspection occurs again for the next units and this continues until finding the " $i$ " consecutive units without defects.

3. The defective units detected have to be replaced or corrected for good ones.

The concept, known as AOQL (Average Outgoing Quality Level), was first conceived as a response to the necessities that came from certain circumstances during manufacturing and represents the limit or upper level of average quality produced in accepted lots. When the quantity of the lot is specified, similar to the case of lots of clients, the concept is applicable but it is also applicable when the lot inspected is a subdivision of a convenient flow of products.

\section{INITIAL STATISTICAL MODELS DONE IN THE INVESTIGATION}

The direct relation between CSP-1 sampling plans and the probability theory can be defined in time through the conditions of stable state in the Markov processes and the Bayesian theory, defining two possible states: E1 or $100 \%$ inspection state and E2 or fractional inspection state (systematic sampling). The following describes a probability matrices of transition of a chain generated with the two states E1, E2, where $\mathrm{P}^{\prime}$ corresponds to the fraction of products with non conformities of the line of production.

Table 1: Matrix of transition probabilities, the analysis of a CSP-1 plan with Markovian processes

\begin{tabular}{|c|c|c|}
\hline & E1 & E2 \\
\hline E1 & $1-\left(1-\mathrm{P}^{\prime}\right)^{\mathrm{i}}$ & $\left(1-\mathrm{P}^{\prime}\right)^{\mathrm{i}}$ \\
\hline E2 & $\mathrm{P}^{\prime}$ & $1-\mathrm{P}^{\prime}$ \\
\hline
\end{tabular}

The Bayesian revision of the CSP plans take part of an assumption of one hypothesis. Since it starts with a statistical hypothesis, it is defined that there can exist products that meet the standards and those with non conformities and that the inspector or tool installed in the line of production determines that it really can be accepted or rejected, respectively. This differentiation of the products, taken by the inspector must be at the end tested with a known one to confirm the effectiveness of the plan and the inspector. These instances calculated and described by the condition previous to this one, describe the statistical states of the Markov chain that will probably surge as a response to an event.

For the initial statistical model it can be defined:

- $\mathrm{Q}_{\mathrm{i}}, \mathrm{i}=1,2$ where: $\mathrm{Q}_{1}=$ acceptable products; $\mathrm{Q}_{2}=$ products with non conformities

- $\mathrm{S}_{\mathrm{j}}, \mathrm{j}=1,2$ where: $\mathrm{S}_{1}=$ The inspector (tool) says "Accepted"; $\mathrm{S}_{2}=$ The inspector (tool) dice "Rejected"

The model includes two type of conditional probabilities: one for the prediction, $\operatorname{Pr}(\mathrm{Qi} / \mathrm{Sj})$, and the other for the testing, $\operatorname{Pr}(\mathrm{Sj} / \mathrm{Qi})$. Among the conditional probabilities of prediction, the possible combinations of prediction of the inspection are: $\operatorname{Pr}(\mathrm{Q} 1 / \mathrm{S} 1) ; \operatorname{Pr}(\mathrm{Q} 1 / \mathrm{S} 2) ; \operatorname{Pr}(\mathrm{Q} 2 / \mathrm{S} 1) ; \operatorname{Pr}(\mathrm{Q} 2 / \mathrm{S} 2)$. While the conditional probabilities for testing include: $\operatorname{Pr}(\mathrm{S} 1 / \mathrm{Q} 1) ; \operatorname{Pr}(\mathrm{S} 1 / \mathrm{Q} 2)$; $\operatorname{Pr}(\mathrm{S} 2 / \mathrm{Q} 1) ; \operatorname{Pr}(\mathrm{S} 2 / \mathrm{Q} 2)$. To illustrate this better, the concepts for conditional probabilities are described under the following expressions:

- Prediction: $\operatorname{Pr}(\mathrm{Q} 1 / \mathrm{S} 2)=$ Units retained unfairly, since they resulted from accepted products given that, given the decision of the inspector, they were separated as non conformities.

- Validity: $\operatorname{Pr}(\mathrm{S} 1 / \mathrm{Q} 1)=$ Units that the inspector, given the ignorance to the hypothesis, makes a right decision when accepting or rejecting the product. 
DESCRIPTION AND DEVELOPMENT OF THE PROBLEM STUDIED

For the application of these models, the production of an important business from the pharmaceutical industry of the city of Barranquilla was chosen.

\subsection{Evaluation of the predictive capacities of the inspectors}

During the evaluation of the predictive capacities of the inspectors, values were taken from a $100 \%$ inspection process of one type of product on the business, for which the following results were obtained:

$$
\begin{aligned}
& \operatorname{Pr}(\mathrm{S} 1 / \mathrm{Q} 1)=0.995 \\
& \operatorname{Pr}(\mathrm{S} 2 / \mathrm{Q} 1)=0.005 \\
& \operatorname{Pr}(\mathrm{S} 2 / \mathrm{Q} 2)=0.7246 \\
& \operatorname{Pr}(\mathrm{S} 1 / \mathrm{Q} 2)=0.2754
\end{aligned}
$$

Previously, through statistical quality control methods, the proportion of non conformities for the product studied was established as 0.0038 . Having this, $\operatorname{Pr}\left(\mathrm{Q}_{1}\right)=0.9962$ and $\operatorname{Pr}\left(\mathrm{Q}_{2}\right)=0.0038$ and by applying the Bayesian Theory, the values for $\mathrm{S}_{1}$ and $\mathrm{S}_{2}$ can be calculated. For example, for $\mathrm{S}_{1}$,

$$
\operatorname{Pr}\left(\mathrm{S}_{1}\right)=\operatorname{Pr}\left(\mathrm{Q}_{1}\right) * \operatorname{Pr}\left(\mathrm{S}_{1} / \mathrm{Q}_{1}\right)+\operatorname{Pr}\left(\mathrm{Q}_{2}\right) * \operatorname{Pr}\left(\mathrm{S}_{1} / \mathrm{Q}_{2}\right)=0.9922 .
$$

Following the same procedure with $\mathrm{S} 2$ it is found that $\operatorname{Pr}(\mathrm{S} 2)=0.0078$.

\subsection{Displayed Lists}

A displayed list is a list that is set off from the text, as opposed to a run-in list that is incorporated into the text. The bulleted list given below provides more information about the format of a displayed list.

- Use standard bullets instead of checks, arrows, etc. for bulleted lists.

- For numbered lists, the labels should not be Arabic numbers enclosed in parentheses because such labels cannot be distinguished from equation numbers.

- You may need to restart the numbering on numbered lists. To do so, right click on the first entry in the list.

\section{3 $\quad 3.2$ Cost sensibility analysis}

The total unit cost of the product analyzed is of $1.4841 \mathrm{~A}$ and the size of the lot is 200,000 units. The purpose of this analysis is to examine the costs incurred for rejection of products that meet with the standards of the client that are due to a human error and the dispatching of products with non conformities.

The number of units retained by mistake comes from the following probability:

$$
\operatorname{Pr}\left(\mathrm{Q}_{1} / \mathrm{S}_{2}\right) * \mathrm{~N}=\frac{\operatorname{Pr}\left(\mathrm{Q}_{1}\right) \times \operatorname{Pr}\left(\mathrm{S}_{2} / \mathrm{Q}_{1}\right)}{\operatorname{Pr}\left(\mathrm{S}_{2}\right)} \mathrm{N}=487.1794
$$

Given that each unit has a cost of $1.4841 \mathrm{~A}$, the total costs incurred in the retention of products due to a human error are 723.019A. The costs generated by dispatching defective units are summarized in the following table:

Table 2: Costs generated for non-conformities dispatched

\begin{tabular}{|c|c|c|c|l|l|}
\hline $\begin{array}{c}\text { No. defective units } \\
\text { dispatched }\end{array}$ & $\begin{array}{c}\text { Manuf. } \\
\text { Costs }\end{array}$ & $\begin{array}{c}\text { Transp. } \\
\text { Fees }\end{array}$ & Insurance & $\begin{array}{c}\text { Total } \\
\text { Cost }\end{array}$ \\
\hline $\operatorname{Pr}\left(\mathrm{Q}_{2} / \mathrm{S}_{1}\right)^{*} \mathrm{~N}$ & 210.945 & $313.07 \mathrm{~A}$ & 247824 & 82608 & $\begin{array}{l}313.07 \mathrm{~A}+ \\
330432\end{array}$ \\
\hline
\end{tabular}

This cost is approximated to $\$ 361,736$, given the case where all units with non conformities that were dispatched were rejected and returned by the client. Given the case that this result repeated itself many times with different clients, it can lead to significant losses for the business. 


\subsection{Markovian Analysis}

The AQL established for the client is of $0.25 \%$, while the proportion of non conformities for this process is of $0.38 \%\left(\mathrm{P}^{\prime}\right)$. Given that AQL is less than $\mathrm{P}^{\prime}$, it can be concluded that a CSP-1 plan works for this business. For the application of this model, there will be an i corresponding to 1.245 , having in mind that the AQL is of $0.25 \%$ and the fraction for inspection is of $10 \%$. As was indicated previously, the sampling plan CSP-1 represents a Markovian process whose transition probabilities are shown in Table 1. The intention now is to analyze the results that could be obtained if the inspector were perfect, this means, with a null probability of making mistakes. If the fraction of detected non conformities in a product were P', the comparison of these results with the ones obtained in the practice, gives that the inspector detects defective units with probability, S2 P'. After some calculations done, the resulting transition matrices are:

Table 3: Values for transition probabilities for $\mathrm{S}_{1}$ and $\mathrm{S}_{2}$.

\begin{tabular}{|c|c|c|}
\hline & \multicolumn{2}{|c|}{ P' } \\
\hline & E1 & E2 \\
\hline E1 & 0.9912 & 0.0087 \\
\hline E2 & 0.0038 & 0.9962 \\
\hline
\end{tabular}

\begin{tabular}{|c|c|c|}
\hline & \multicolumn{2}{|c|}{ S2 } \\
\hline & E1 & E2 \\
\hline E1 & 0.99994 & $5.83 * 10-5$ \\
\hline E2 & 0.0078 & 0.9922 \\
\hline
\end{tabular}

Equations in a stable state:

$$
\begin{gathered}
\mathrm{P}^{\prime}: X_{100}^{*}=0.9912 X_{100}^{*}+0.0038 X_{f}^{*}(1) ; X_{f}^{*}=0.0087 X_{100}^{*}+0.9962 X_{f}^{*}(2) ; X_{100}^{*}+X_{f}^{*}=1(3) \\
\mathrm{S} 2: X_{100}^{*}=0.99994 X_{100}^{*}+0.0078 X_{f}^{*}(1)
\end{gathered}
$$

Taking into account the real fraction of non conformities of the process, $\mathrm{P}$ ', by solving the previous equations it is obtained for $\mathrm{X} 100^{*}=0.3030$ and $\mathrm{Xf}^{*}=0.6970$, which means that the $30.3 \%$ of the times, $100 \%$ inspection is done and the $69.7 \%$ remaining is employed in partial inspection. Yet, at the time the plan was applied, the fraction of units that were identified as non conformities were not precisely P', but S2. Similarly, when solving the equations mentioned above, it was obtained for $\mathrm{X} 100^{*}=0.9925$ and $\mathrm{Xf}^{*}=0.0075$. By interpreting these results, it turns out that really a $99.25 \%$ of the times $100 \%$ inspection is used and that the remaining $7.5 \%$ is employed in partial inspection.

The expected number of units inspected $=\mathrm{Q} x$ (portion of the time it takes in $100 \%$ inspection) $+\mathrm{Q} x$ (portion of the time it takes in partial inspection). By solving this case in which there existed a real fraction of the process P', it is obtained that the expected number of inspected units could be 74,540 units, while in the practice, the number expected was of 198,650 units. If the cost for inspection is of $5 \$$ unit, the real cost associated to the inspection plan is $\$ 372,700$ that could occur if the inspector didn't make a mistake. Unfortunately and according to the Second Law of Thermodynamics and the Principle of Uncertainty of Heisenberg, it is not possible to have perfect inspectors and if there were, it is impossible to demonstrate it.

\section{CONCLUSIONS}

Throughout the analysis done in this investigation, it could be observed how much someone or a business is willing to sacrifice in money for making the wrong decisions considering $100 \%$ correct the predictions done by the inspectors, inspecting tools and machines. By allowing these decision errors, the inspector can unfairly retain products that meet the standards of the client given by $\operatorname{Pr}(\mathrm{Q} 1 / \mathrm{S} 2)$, where the cost associated to this mistake represent the cost of manufacturing of additional units that should have been dispatched. On the other hand, it can happen that the units with non conformities were dispatched, with a probability of $\operatorname{Pr}(\mathrm{Q} 2 / \mathrm{S} 1)$, which means unnecessary costs of shipping and could cost penalties given by the clients.

Additional to this, it was seen that the effect of the sampling plan considers a probability of rejection of the inspector (S2), which is bigger than the probability P' of the process. In this case of study, this observation causes that the probability that maintains the $100 \%$ inspection be greater than 0.006895 , with respect to the case that it were worked with a real fraction 
of non conformity of the process. This means that it will continue to inspect the $100 \%$ of the units more time than the necessary, given the fraction of non conformity of the process, which logically refers to an increase in the costs of inspection.

After having done all of this analysis, it could be demonstrated the importance of testing the determination by an inspector between products that meet the standards of the client and those that don't meet them, compared to the real truth that confirms the effectiveness of the plan and the inspector. For this, it could be possible to apply conditions of prediction that can reduces, the most, the delivery of products with non conformities and the costs associated to the inspections done.

\section{ACKNOWLEDGMENTS}

This paper was supported by the Colombian Institute for Development in Science and Technology "Francisco José de Caldas" (COLCIENCIAS), under the Project 1215-08-17730.

\section{REFERENCES}

ANSI/ASQC S2. 1995. Introduction to Attribute Sampling. American Society for Quality. Milwaukee.

Balamurali, S. 1999. Modified Two Level continuous Sampling Plans. Annals of Mathematical Statistics. Vol 36, p.14081420.

Besterfield Dale H. 1994. Control de Calidad (Quality Control). 4th edition. Prentice Hall. Bidyuk, B. and Dechter, R. 2003. Cycle-Cutset Sampling for Bayesian Networks. Sixteenth Canadian Conference on Artificial Intelligence.

Brugger, R.M. 1972. A Simplification of the Markov Chain Approach to continuous Plan Formulation, Report No. QEM 21230-12, Ammunition Procurement and Supply Agency. Joliet, Illinois.

Dodge, H. F. and Torrey, M. N. 1951. Additional Continuous Sampling Inspection Plans. Industrial Quality Control, Vol. 7, pp. 7-12.

Gallagher Charles A. and Watson Hugh J. 1991. Métodos cuantitativos para la toma de decisiones (Quantitative methods for decision making). 2nd edition. McGraw Hill. Mexico City.

Govindaraju K. 2007. Inspection error adjustment in the design of single sampling attributes plan. Quality Engineering 19 $227-233$

Helderman and Verlag. 2002. Economic Quality Control: Combining Process and Product Control for Reducing Sampling Costs. ISSN 0940-5151, Vol 17, No.2, p.187-194.

Hillier,F y G.J. Lieberman. 1990. Introduction to Operations Research. 5th edition, Mc Graw Hill. New York.

Hodson William K. 1996. Manual del Ingeniero Industrial MAYNARD (A Guide for an Industrial Engineer). 4th edition. McGraw - Hill, Mexico City.

Juran J.M., Godfrey A. B. 2001. Manual de Calidad (The Quality Manual). 5th edition. Mc Graw Hill. Vol. 2, Madrid.

Lieberman, G. J. and Solomon, H. 1955. Multi-level Continuous Sampling Plans. Annals of Mathematical Statistics, Vol. 26, pp. 686-704.

Roberts, S.W. 1965. States Of Markov Chains for Evaluating Continuous Sampling Plans. Transactions of the 17 Annual all Day Conference on Quality Control, Metropolitan Section ASQC \& Rutgers University, NJ , 106-111.

Walpole R. E y R.H Myers. 1989. Estadística y Probabilidad para ingenieros y cientificos (Statistics and Probability for engineers and scientists). 4th edition. Mc Millan, New York. 